Article

\title{
Interdependencies of Culture and Functions of Sustainability Governance at Higher Education Institutions
}

\author{
Mara Bauer ${ }^{1, *}$, Sebastian Niedlich ${ }^{2}\left(\mathbb{D}\right.$, Marco Rieckmann $^{1}{ }^{(\mathbb{D}}$, Inka Bormann ${ }^{2} \mathbb{(}$ \\ and Larissa Jaeger ${ }^{1}$ \\ 1 Department of Education, Faculty of Education and Social Sciences, University of Vechta, Driverstraße 22, \\ 49377 Vechta, Germany; marco.rieckmann@uni-vechta.de (M.R.); larissa.jaeger@uni-vechta.de (L.J.) \\ 2 Department of Education and Psychology, Freie Universität Berlin, Habelschwerdter Allee 45, \\ 14195 Berlin, Germany; sebastian.niedlich@fu-berlin.de (S.N.); inka.bormann@fu-berlin.de (I.B.) \\ * Correspondence: mara.bauer@uni-vechta.de
}

Received: 28 February 2020; Accepted: 31 March 2020; Published: 1 April 2020

\begin{abstract}
Sustainable development practices in higher education institutions are diverse, with regard not only to the types of challenges that have to be addressed, but also to the forms of sustainability governance adopted by individual higher education institutions. This paper aims to reflect on the aspects of organizational culture that are particularly crucial for the implementation of sustainable practices at higher education institutions. Specifically, it addresses the research question: how do different organizational cultures affect approaches to sustainability governance at higher education institutions (HEIs)? It reflects on data from multi-case studies at eleven German higher education institutions. Four of the cases are analyzed in this paper to draw out the insights they offer on how organizational culture shapes the institutions' approach to sustainable development. A governance equalizer is used as a functional framework for evaluating and discussing the influence of different cultural orientations on sustainability governance. In addition to providing many insights and findings in relation to specific cases, comparison of the different institutions, their governance structures and their cultures of sustainable development helps to emphasize that there is no single cultural factor that can be identified as directly promoting particular governance structures. Rather, there is an active interplay between cultural orientations, which influence, and are also influenced by, the measures deployed. Such influence is not instantly apparent but needs time to develop, and it evolves in a variety of ways as illustrated by the case studies.
\end{abstract}

Keywords: sustainability governance; higher education; organizational culture; governance equalizer; Germany

\section{Introduction}

The aspiration of integrating sustainable development (SD) into the structures and processes of higher education institutions (HEIs) while taking account of all their different fields of activity, such as research, teaching, outreach, and operations, has been recognized in practice and research alike as a complex and highly context-dependent task [1-4]. The definitions of sustainable development in the context of higher education institutions remain as rhetorically malleable and as fluid as those in public and political discourse [5]. As a result, SD practices in HEIs have been diverse, not only with regard to the types of challenges that have been addressed, but also in respect of the forms of governance that have been established to coordinate the approach to such challenges (e.g., [6]). Attempts to classify SD implementation structures within HEIs (e.g., $[7,8]$ ) have, along with other literature, highlighted 
the need for a shared commitment to sustainability goals, structures and processes amongst HEI staff, covering teaching, research and operations-in other words, the need for holistic governance [9].

Following that line of argument, HEI governance for sustainability aims to promote and support the changes institutions need to put in place to embed SD in their organizations. It is concerned with all the circumstances, pathways and methods by which sustainability reaches and permeates HEIs. At the core of these processes are the people that make up HEIs. The HEI and its sustainability pathway are essentially comprised of their ideals, vision and engagement, and the ways they communicate and consult [10-12]. This deserves special attention.

Since sustainable development is a complex concept, and HEIs are complex organizations, it is important to be aware of the implications and requirements of a thorough and comprehensive approach to the introduction of SD. For many HEIs, it will presumably mean making a number of fundamental changes within the institution. In this context, the word 'transformation' is not an exaggeration but a prerequisite [13,14]. Cameron and Quinn [15] stress the notion that the best way of implementing such major organizational changes is to take the organizational culture into account and shape it in a way that supports such change. "Although the tools and techniques may be present and the change strategy implemented with vigour, many efforts to improve organizational performance fail because the fundamental culture of the organization - values, ways of thinking, managerial styles, paradigms, approaches to problem solving - remains the same" [15] (p. 11). The failure to achieve organizational change often has ramifications for members of organizations, and could mean that their response to future change initiatives might be even less cooperative [15].

While Cameron and Quinn are concerned with organizational change in general, other research supports their findings in the particular context of sustainable development in HEIs $[16,17]$. HEIs need to find ways to embed SD into their specific norms and values and into the shared goals of their members, and to create common ground so as to enable their organizations to learn sustainability, learning being essential to the achievement of a paradigm shift [18]. Even though HEIs might be considered experts in learning, this does not necessarily apply to their capacity to learn for and about themselves [17].

As Adams et al. clearly state, "the failure to embed sustainability in HEIs suggests it has failed to become part of the culture" [16] (p. 2). We, therefore, seek to investigate whether this suggestion is supported by the experiences of HEIs, and, more specifically, which kinds of cultural variables feed into which governance structures. Organizational culture in general can be considered an integral part of sustainability governance, since each HEI has a specific mode of engagement with SD depending on its prior experiences, its code of communication, its resources in terms of expertise and time, its recognition of SD as an opportunity for profiling, its perception of public pressure on the HEI, etc. It is, therefore, appropriate to discuss the functions and cultures of sustainability governance at HEIs in greater detail.

Accordingly, this paper explains and brings together two different perspectives on sustainability governance at HEIs: culture and functions. Special attention is paid to the impact that certain organizational cultures have on the development of aspects of functional governance at HEIs, i.e., the structures, processes and environment that are created there. The corresponding research question is: how do different organizational cultures affect approaches to sustainability governance at HEIs?

Against this backdrop, we aim to investigate distinct aspects of organizational culture that are particularly crucial to the implementation of SD at HEIs. In this context, we are taking, as our basis, our earlier work in which we prepared two major frameworks-one on culture [19] and one on functions [2] - and which we will bring together in this paper. We identified two types of cultural orientation that are usually prevalent in HEIs in relation to the attitudes, assumptions and practices that they bring to SD implementation [19]. These are summarized in Section 2.1 and followed in Section 2.2 by an introduction to the governance equalizer, an HEI sustainability governance concept that we used in this paper as a functional framework for evaluating and discussing the significance of the cultural orientations in question. Section 2 thus provides an overview of the frameworks deployed in the analysis that follows. 
The foundation for evaluating the various aspects of HEIs' approaches to implementing SD was guided and supplemented by desk research but consisted primarily of extensive empirical research on sustainability governance at eleven German HEIs, which resulted in eleven different case studies. The methodology and research process that eventually led to this paper are described in Section 3. Having laid the groundwork for a combined analysis of the cultural and functional aspects of SD governance in HEIs, Section 4 introduces four of the eleven case studies and investigates how the HEIs' organizational cultures are interlinked with their processes and structures for SD implementation. The subsequent discussion and conclusion highlight the main learning points, merits, limitations, and outstanding or emerging questions.

\section{Frameworks on Culture and Functions of Sustainability Governance at HEIs}

\subsection{Cultural Orientations}

Initially, basing ourselves on qualitative content analysis, we derived four cultural dimensions from our interview material, which were then conflated into two overarching cultural orientations that distinguish the way in which HEIs face the challenges of SD: holistic orientation and organizational learning orientation [19].

\section{- Holistic orientation}

This category combines the two dimensions conception of sustainability and relevance and scope of organizational change. Both dimensions emphasize the need to consider different elements simultaneously, and to link them in an integrated approach. Thus, we use the term holistic not as a philosophical concept, but to refer to the comprehensiveness of the HEI's orientation towards SD.

Conception of sustainability refers to the understanding that an HEI has of the comprehensiveness of SD. Does the HEI include ecological viability, social justice and economic capacity alongside each other in its long-term responsibilities? A variety of professional perspectives at an HEI might come with a variety of conceptions of sustainability that often focus almost exclusively on one of these dimensions of sustainability instead of taking an integrated approach [20]. The HEI's willingness to combine these perspectives and find common ground to start from can open up new spaces and options for SD that can be discovered and seized [21].

Relevance and scope of organizational change refers to an HEI's idea of where SD should be implemented. Viewing the HEI as a single system whose subsystems such as teaching, research, operations and outreach are given equal footing as fields of activity for SD (whole-institution approach) is deemed crucial [22,23]. As with the conception of sustainability, this dimension deals with the question of comprehensiveness. While the first is concerned with the content of SD, the latter considers the context. Taken together, the two dimensions, therefore, represent the holistic ideal inherent in the concept of sustainable development.

\section{- Organizational learning orientation}

This category combines the dimensions attribution of responsibility and purpose of the higher education institution.

The focus is on the degree to which SD is seen as an issue of organizational development and learning which, firstly, can be represented by the attribution of responsibility for SD. In this context, the call for collaborative and co-creative processes receives broad support $[10,21,22,24,25]$. SD should not be reserved to the institution's elite, but based on the approval and engagement of many [22] and, therefore, handled by means of shared responsibilities and co-determination. This also entails the institution's leadership taking an open-minded approach to the emergence of innovative ideas and unexpected developments in relation to SD from different members of the HEI and to taking SD ideas and goals seriously by fostering discussions [26]. 
Another aspect of organizational learning derives from the way an HEI perceives itself and its role in the societal context: the purpose of the higher education institution. Trencher et al. [27] have coined the term "fourth mission" as a description of the sustainable HEI's role in society: a debater, a networker, and a transformer. HEIs can actively promote co-creation of societal transformation that goes far beyond technology transfer and other economic contributions, which is mostly what the third mission concept has been requesting and seeking to pursue. The idea of a "fourth mission" takes HEIs" role in society further towards active engagement and mutual learning. If an HEI takes on this role, its chances of transforming itself as an institution and achieving a higher level of SD improve. This is especially true when active engagement and mutual learning are paired with participatory processes, since this creates an environment that promotes critical, systemic and future-oriented thinking.

On the basis of our findings, we had assumed that the two orientations had a linear relationship and tended to mutually reinforce each other [19], but, so far, we have not taken a closer look at their implications for the structures, procedures and measures of sustainability governance at HEIs. How are HEIs' sustainability governance set-ups influenced by different cultural orientations? The next section will introduce a functional framework that forms the basis of the subsequent analysis of this question.

\subsection{Depicting the Functions of Sustainability Governance through a Governance Equalizer}

In order to illustrate governance structures within institutions, de Boer et al. [28] use the image of a piece of audio engineering equipment, known as an equalizer. Instead of base, reverberation or volume, this particular equalizer is equipped with slide controls that display different dimensions of institutional governance and the performance of the institution against each dimension, or functional requirement. In analyzing sustainability governance at HEIs, we draw on Franz and Brüsemeister [29], and have chosen five dimensions for our equalizer: politics, profession, organization, knowledge, and public [2].

The following overview gives a brief outline of the equalizer dimensions which are the result of combining the original heuristic with its representation within our case studies.

1. Politics: How is sustainability implemented and legitimized within and outside the HEI?

This equalizer dimension deals with the question of how sustainability activities are not only selectively supported, but form part of an HEI's long-term development goals. The term politics should not be misunderstood: it does not refer to the state-level measures that set the overall framework for higher education institutions, but to the actions of the HEI members themselves. In order to embed $\mathrm{SD}$, formal and informal decisions and resolutions are required that are binding on as many actors at the HEI as possible. Such definitions give legitimacy to those who are pursuing SD, providing a basis for their actions. They provide goals and standards that act as guidance for sustainability-related activities, and can serve as a basis for reviewing the success of such activities. Collectively binding decisions can be taken both by the hierarchy and as part of participatory processes.

2. Profession: How are professional perspectives and competencies linked?

The dimension of profession is about the gradual development of an interdisciplinary and cross-sectoral understanding of sustainability at an HEI. The different areas of activity at HEIs-teaching, research, and campus management (administration, technology, etc.) — have very different requirements, processes and framework conditions, demand different competencies and specialist knowledge, and have their own standards and 'cultures'. The scientific disciplines also differ considerably in this regard, as do the external actors HEIs are involved with. However, SD requires that internal and external actors work closely together. This facilitates exchanges of views on what SD should include, what principles and standards should be taken into account, and how SD can be integrated into the day-to-day practices of different activities and disciplines. 
3. Organization: How are collaborative work and task processing made possible?

In order to encourage SD in HEIs, it is necessary to specify goals and activities that facilitate implementation. This involves providing resources and creating structures and processes that ensure continuous and reliable work. In the context of $\mathrm{SD}$, it is important to ensure long-term action across existing organizational boundaries - between different areas of activity as well as with non-academic actors. To do so, it is necessary to network actors and to coordinate their activities.

4. Knowledge: How is the required knowledge developed and used competently?

$\mathrm{SD}$ in higher education requires consideration of the complex issue of knowledge. The actors in HEIs have to develop shared ideas about what the problems are and what has caused them (analysis), they have to agree on how the situation is to be evaluated and what the aims will be in the future (goals). It is also important to clarify which measures will be used to solve problems (action). Alongside technical and professional expertise, knowledge of different actors' responsibilities, structures and processes at an HEI plays an important role in clarifying how measures can be best implemented. At the same time, each solution usually entails specific advantages and disadvantages. This means that deciding which measures to implement involves a normative judgment. It is not sufficient, therefore, for the sustainability governance at HEIs to access knowledge only in times of need. Instead, ways must be established to identify, disseminate, and use the relevant knowledge on a continuous basis in order to be able to react flexibly when problems arise and to facilitate longer-term learning processes. This requires more than technical solutions-it also involves collaboration and networking with the aim of supporting exchange and joint knowledge work.

5. Visibility: How is awareness of the need for sustainable development in HEIs created?

Making an HEI's sustainability efforts visible to the internal and external public plays an important role in SD governance, as it provides the opportunity for all the institution's stakeholders to observe and respond to issues and positions as well as activities and their outcomes. Public attention can thus contribute to greater participation in and awareness of SD, such as identifying the need for action, communicating and justifying goals and actions, and reporting on progress. Last but not least, in this way, the importance of sustainability for the HEI can be demonstrated and sustainability can become an important element of an HEI's profile and thus help to attract students or external partners.

We will consider the specific interplay of organizational culture and the implementation of SD at different HEIs against this framework. This paper will, therefore, analyze four cases relating to the ways in which cultural orientation trickles down and can influence the structures and processes that are being established to promote $\mathrm{SD}$, and that then become visible in the governance equalizer. The general assumption that can be made at this point is that a strong cultural orientation towards $\mathrm{SD}$ leads to better and more coherent SD governance. How this can take place in different real-world contexts is shown in detail in Section 4.

\section{Methodology}

This paper is based on the findings of two earlier papers [2,19] that stem from the same research. The first [2] sought to validate the governance equalizer through ten expert interviews; this was then used as a theoretical basis for the evaluation of 61 stakeholder interviews. The second [19] focused on the evolution of categories from this extensive interview material, namely the development of an empirically-based categorization of the characteristics of sustainability governance in HEIs, and further condensation into two cultural orientations. Both the governance equalizer and the two categories of cultural orientations are explained above.

In order to answer the research question for this paper, "How do different organizational cultures affect approaches to sustainability governance at HEIs?", four exemplary HEIs were selected for the purpose of analyzing and illustrating the effect of organizational cultures on governance structures 
and processes. The selected cases (described in Section 3.3) are divided into two pairs of HEIs that appeared to offer promising insights into the effect of cultural orientations on sustainability governance after being categorized in Niedlich et al. [19].

The following description of the research process gives an overview of the whole process, and then focuses on the measures that were taken in order to achieve insight into the interplay of cultural orientation and the governance equalizer. By combining the perspectives of culture and functions from the two earlier papers and the frameworks that these established, and feeding them with the four case studies, our aim is to deepen understanding of the significance of organizational culture for SD at HEIs in general, but also with respect to specific functions within HEI SD governance.

\subsection{Data Collection}

The study that provided the insights outlined above on sustainability governance and organizational culture for SD at HEIs looked at the experiences of, and observations from, eleven German HEIs. These HEIs are all members of the joint research project "Sustainability at Higher Education Institutions: develop-network-report" $\left(\mathrm{HOCH}^{\mathrm{N}}\right)$ which, in addition to sustainability governance, focuses on research, teaching and operations as well as on the transfer of SD-related knowledge and approaches (see https://hoch-n.org/en).

The research design consisted of face-to-face interviews with different actors at the eleven HEIs. Interview partners were chosen on the basis of selective sampling. In order to gain an in-depth understanding and to incorporate different views and perspectives on sustainability governance, 61 stakeholders from the following groups were interviewed:

- HEI management (11 interviews),

- SD coordinators/commissioners/managers (10 interviews),

- Student initiatives (14 interviews),

- Technical administration (14 interviews), and

- Academic staff (professors and researchers) (12 interviews).

In addition to time and willingness to participate, selection criteria included knowledge and first-hand experience of their institution's sustainability process (cf. [30]). The interviewees were identified and recruited in collaboration with our partners within the $\mathrm{HOCH}^{\mathrm{N}}$ network as well as through desktop research. The sample is thus limited by the number of project partners. These provided an interesting sample, as they all were willing to participate in the interviews, had sufficient range of stakeholders involved in the sustainability process at their institutions and hence could provide a variety of perspectives. Although the sample is not representative of all HEIs in Germany, as the participation in the $\mathrm{HOCH}^{\mathrm{N}}$ project already implies a bias towards a stronger commitment to sustainability, it shows interesting cases, with very different approaches to the organization of sustainability.

The interviews were conducted using an interview guide consisting of five sections, each containing one key question and supplementary questions. The five sections were:

1. Development of the sustainability process;

2. Importance of specific actors, structures and processes;

3. Sustainability as a guiding principle for the HEI;

4. Assessment of the sustainability process;

5. Assessment of the stakeholder network by means of the governance equalizer heuristic.

Of the 61 interviewees, 30 were female and 31 were male. As the study was designed on a cross-sectional basis, all individuals were interviewed only once. The average duration of an interview was 47 minutes. All interviews were recorded and transcribed using a simplified approach [31]. 


\subsection{Data Analysis}

The material was analyzed in several successive phases. As an initial step, data from the eleven case studies were analyzed using qualitative content analysis [32]. To ensure that data were adequately analyzed and interpreted, all phases of the analysis involved a minimum of two researchers and data analysis and interpretation was validated between researchers using a communicative process (cf. [33]).

First, a qualitative thematic text analysis was conducted, using primary categories derived from the interview guide. After coding data in line with these and other deductive categories from three HEIs, additional categories and subcategories were created. The data from all eleven cases were coded using the revised categories and category-based analysis was undertaken, creating thematic summaries for all coded text segments.

On this basis, case profiles were produced, which, in addition to a timeline for SD processes, included findings on the state of SD activities, initiatives and actors, motives and objectives, views on the societal role of HEIs, influencing factors (structural/institutional, process related, personnel, HEI size, external), and factors of particular interest in relation to specific cases. The case profiles were used to carry out thematic cross-case analysis with the aim of identifying differences and similarities (Figure 1).

\begin{tabular}{|c|c|c|c|c|c|c|}
\hline $\begin{array}{l}\text { Testing and } \\
\text { establishing the } \\
\text { theoretical basis } \\
\text { (i.a. governance } \\
\text { equalizer) for the } \\
\text { study via ten } \\
\text { expert interviews }\end{array}$ & $\begin{array}{l}\text { Development of } \\
\text { an interview } \\
\text { guide and } \\
\text { identification of } \\
\text { stakeholders to } \\
\text { be interviewed }\end{array}$ & $\begin{array}{c}61 \text { stakeholder } \\
\text { interviews at } \\
11 \text { higher } \\
\text { education } \\
\text { institutions }\end{array}$ & $\begin{array}{l}\text { Creation of a } \\
\text { category system for } \\
\text { the qualitative } \\
\text { thematic text } \\
\text { analysis based on } \\
\text { the interview guide }\end{array}$ & $\begin{array}{c}\text { Coding all cases } \\
\text { and creating } \\
\text { thematic } \\
\text { summaries from } \\
\text { which } 11 \text { case } \\
\text { profiles are } \\
\text { derived }\end{array}$ & $\begin{array}{l}\text { Revision of } \\
\text { the } \\
\text { category } \\
\text { system } \\
\text { after coding } \\
\text { three cases }\end{array}$ & $\begin{array}{c}\text { Thematic } \\
\text { cross-case } \\
\text { analysis using } \\
\text { the case } \\
\text { profiles to } \\
\text { inform further } \\
\text { development } \\
\text { of the } \\
\text { governance } \\
\text { equalizer }\end{array}$ \\
\hline
\end{tabular}

Figure 1. Original analysis (focus on sustainability initiatives and governance equalizers) [19].

This led to the identification of four major cultural dimensions of sustainability governance at HEIs [19] characterizing HEIs' conceptions of themselves as institutions as well as their attitudes towards SD (implementation). Each of these cultural dimensions (described briefly in Section 2.1) was then conceptualized as a continuum, ranging from an ideal type of slightest expression to an ideal type of strongest expression. Once every HEI had been located on each of the continuums by means of qualitative content analysis, the results suggested the condensation of the four continuums into two overarching orientations, each comprised of two of the former dimensions (Figure 2).

\begin{tabular}{|c|c|c|c|c|c|}
\hline $\begin{array}{l}\text { Discussion } \\
\text { of themes } \\
\text { emerging } \\
\text { from cross- } \\
\text { case } \\
\text { analysis }\end{array}$ & $\begin{array}{l}\text { Identification of } \\
\text { four key } \\
\text { dimensions and } \\
\text { recoding of } \\
\text { thematic } \\
\text { summaries }\end{array}$ & $\begin{array}{l}\text { Construction } \\
\text { of the four } \\
\text { dimensions } \\
\text { as bipolar } \\
\text { continuums }\end{array}$ & $\begin{array}{l}\text { Situation of } \\
\text { each insitution } \\
\text { on the four } \\
\text { continuums } \\
\text { based on a } \\
\text { scoring system }\end{array}$ & $\begin{array}{c}\text { Comparison of } \\
\text { institutions' } \\
\text { scores suggests } \\
\text { four dimensions } \\
\text { to be combined } \\
\text { into two }\end{array}$ & $\begin{array}{l}\text { Introduction of } \\
\text { two major } \\
\text { organizational } \\
\text { orientations } \\
\text { creating a two- } \\
\text { dimensional space } \\
\text { in which to locate } \\
\text { institutions }\end{array}$ \\
\hline
\end{tabular}

Figure 2. Subsequent analysis (recoding with a focus on the culture of sustainability governance) [19].

At the end of these two analytical phases, two different perspectives on sustainability governance at HEIs emerged: the governance equalizer, with its requirements relating to the functions of sustainability governance, and the organizational orientations crucial to sustainability governance on a cultural level. In order to probe the interrelation of these perspectives, further examination of the case studies appeared necessary and became the aim of this paper.

For that purpose, two pairs of cases were chosen, and their general sustainability processes were compared within each pair; more importantly, the governance structures that the institutions had set up in light of their organizational cultures were also compared. To facilitate this, the case profiles were 
first examined individually for signs in the equalizer dimensions that allowed aspects of the HEIs' cultural orientations to become evident. We then compared the elements that we had identified within each pair to determine the extent to which the different cultures of HEIs had an impact on the design of individual aspects of governance. This acted as the basis for the formulation and discussion of more general assumptions about the interaction of cultures and functions (Figure 3). The reasoning behind the selection of cases is below and is followed by a retracing of the analytical process.

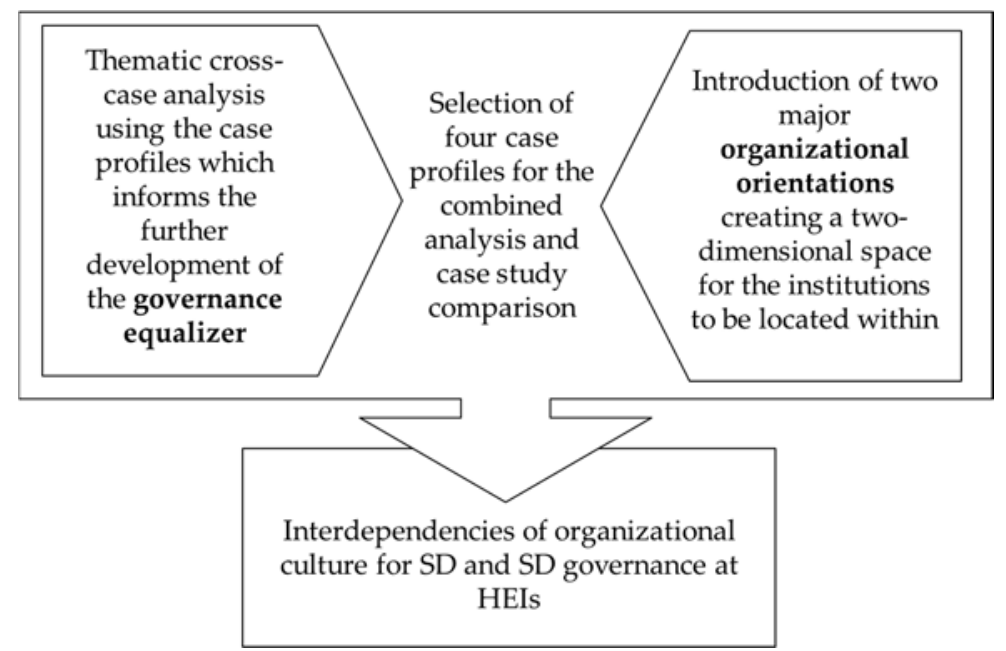

Figure 3. Combined analysis of the cultural orientations and governance equalizer dimensions.

\subsection{Selection of Cases for a Comparative Analysis}

Cases were selected on the basis of Niedlich et al. [19] and the classification of the cultural orientations at the eleven HEIs presented there. From this standpoint, two pairs of HEIs were identified as particularly interesting. They all stemmed from the center ground of the HEIs under consideration, with one pair showing diverging orientations and the other converging orientations in relation to the regression line (Figure 4) that was established for the complete sample of eleven HEIs. It revealed a clear tendency towards a linear relationship between holistic and learning orientation.

Cases VI and VIII were chosen here, for they were the ones that deviated the most from the assumption that holistic orientation and organizational learning orientation are in a linear relationship, but the nature of their divergence was different (note: the numbers of the cases correspond to their use in [19]). Case VI was found to have a more advanced holistic orientation than learning orientation, while case VIII had a culture that was more inclined to promote mutual and inclusive learning and was less focused on having a comprehensive concept of sustainability and all-pervasive processes [19]. We concluded that comparison of the two cases might reveal how the different orientations affected governance structures.

Cases III and IX both supported our assumption of a mutually reinforcing relationship between holistic and organizational learning orientations (Figure 4), but they diverged considerably in their expression of this. In fact, they were the two institutions at the opposite ends of a spectrum of HEIs in the center ground of the sample when cultural orientation was analyzed [19]. The cultural orientation of HEI III towards sustainable development was much less evolved than in HEI IX. It was deemed interesting to compare features of the governance equalizer dimensions for each institution as they related to different stages of development in governance.

Figure 4 situates the four HEIs in a matrix between holistic orientation and learning orientation. Since all four cases demonstrated mid-level performance as far as their cultural orientation towards SD was concerned (compared with the other cases in the sample), the field only ranges from relatively low to relatively high. Together, the four cases represent all of the possible combinations of the two orientations in the matrix (HEI VI = high + low; HEI VIII = low + high; HEI III = low + low; 
HEI IX $=$ high + high). A practical but somewhat coincidental area of common ground between each pair of HEIs is that their current sustainability processes started at similar times and in similar ways. Additionally, all four of the institutions are financed by the state and not privately funded, which also supports their comparability.

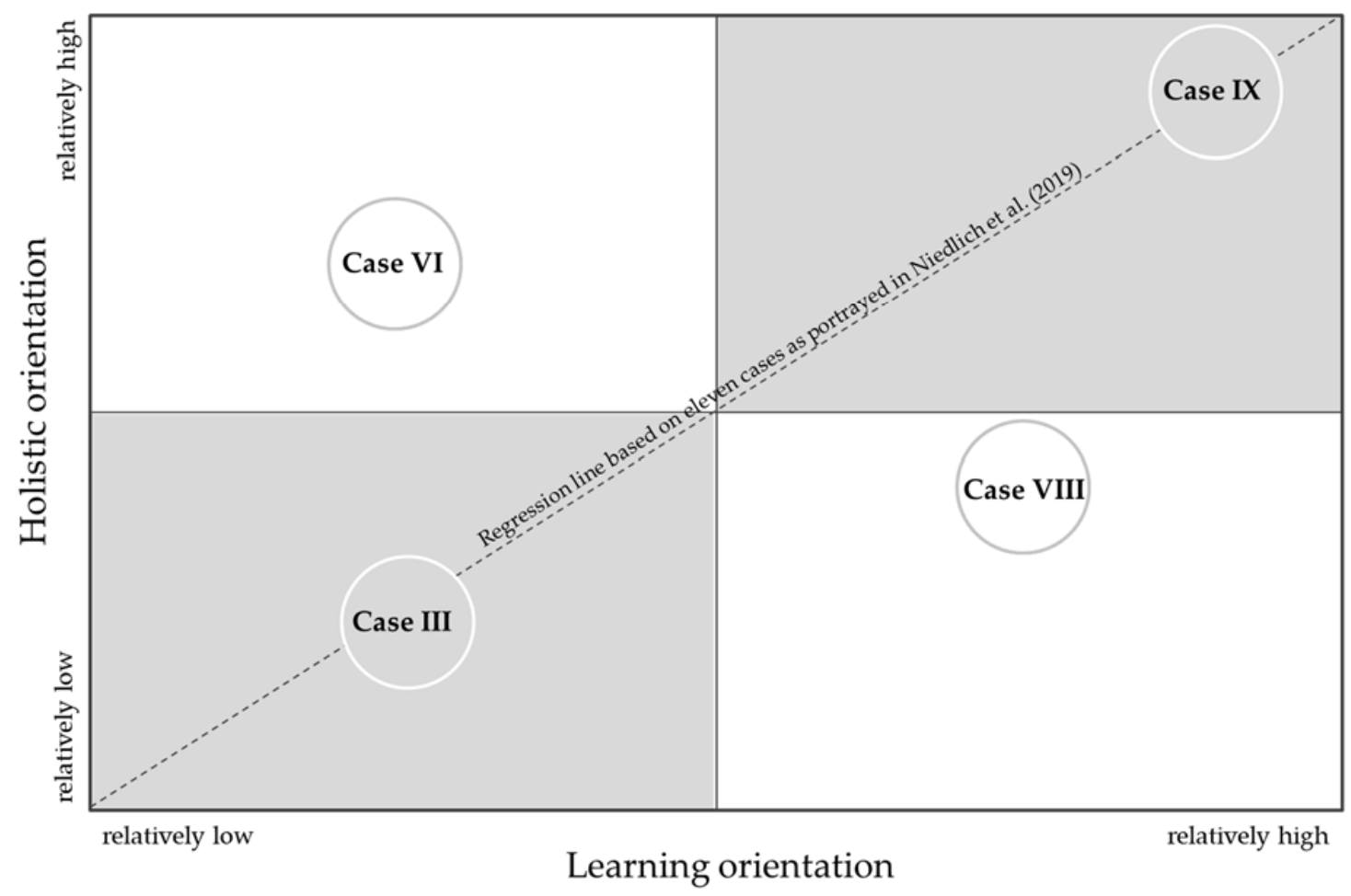

Figure 4. Matrix of selected cases between holistic and learning orientation.

\section{Results}

A comparative analysis of the two pairs of HEIs provides the following insights in respect of the effects of cultural orientation (holistic and learning orientation) on the functional requirements of sustainability governance, as illustrated by the sustainability governance equalizer. The two cases constituting each pair are first described separately and then compared with each other.

4.1. Cases VI and VIII: Strong Holistic Orientation and Pronounced Learning Orientation vs. Low Holistic and Distinct Learning Orientation

Cases VI and VIII were used to gain an impression of the extent to which a difference in the degree of the two cultural orientations impacts on governance structures. Case VI had a stronger focus on holistic orientation and case VIII had a more pronounced focus on learning orientation. While the SD structures and processes that were set up at the two HEIs appear quite similar from the outside, significant differentiation was found. The case descriptions and analyses below explore and draw out, in particular, the differences relating to the manner of structures' outreach into their institution, how autonomous they are and what their conceptual focus is.

\subsubsection{Case VI: Strong Holistic and Low Learning Orientation}

HEI case no. VI has between 5000 and 10,000 employees and between 25,000 and 50,000 students in 100-200 different study programs with a broad spectrum, and is located in an urban environment. The beginning of its sustainability process can be traced back almost 30 years to the early 1990s when concerns about the scarcity of global resource were raised by campus operations staff. Energy efficiency has been on the construction department's agenda ever since, with other environmental issues 
being discussed in a working group specially established for this purpose. From there, sustainability as a concept evolved in HEI VI and was recognized by senior management in recent years as a guiding principle for the whole institution, with the potential to promote and underline its reputation for scientific excellence. A center of expertise was established as the central SD governance body, mediating between senior management and the rest of the HEI. It is comprised of five strategic working groups covering the whole institution and with participation by academic staff, administrative staff and students.

Many activities aimed at creating a sustainable HEI were initiated, including the preparation of a sustainability report and the development of a mission statement. Nevertheless, the HEI's overall SD process is said to be lacking in terms of oversight of the various activities, the transfer of principles into day-to-day practices and broad participation.

Further descriptions of the case are given in Figure 5, which sets the HEI's cultural orientation next to its governance equalizer dimensions. It creates a more comprehensive picture of the HEI's relatively highly developed holistic orientation and relatively underdeveloped learning orientation in relation to SD. Taking all these aspects into consideration, in what ways they might have influenced each other in the particular context of HEI VI can then be discussed.

\begin{tabular}{|l|}
\hline SD Cultural Orientations \\
\hline Learning orientation: The HEI \\
assigns sole authority to senior \\
management in setting the \\
tone for the whole process, \\
has established a centre of \\
expertise that is subject to \\
instructions from above, but \\
seeks to open the process to all \\
$\quad$ HEI members, \\
sees itself as well embedded in \\
society, but its societal \\
engagement is considered a \\
'task for the future'. \\
$\rightarrow$ relatively low expression \\
\hline $\begin{array}{l}\text { Holistic orientation: The HEI } \\
\text { has a long tradition of taking } \\
\text { environmental considerations } \\
\text { into account, and many } \\
\text { different conceptions of } \\
\text { sustainability among its } \\
\text { members, but the centre of } \\
\text { expertise works to unite and } \\
\text { concretize them, } \\
\text { pursues a whole-institution } \\
\text { approach, supported by the } \\
\text { division of the centre of } \\
\text { expertise into different } \\
\text { working groups. }\end{array}$ \\
\hline
\end{tabular}

\begin{tabular}{|c|}
\hline Governance Equalizer Dimensions \\
\hline $\begin{array}{l}\text { Politics } \\
\text { There is an official commitment for SD on the part of senior management, accompanied by } \\
\text { strategies and sub strategies and implemented through the center of expertise. Sustainability } \\
\text { is embedded in the HEI's statutes and in its general mission statement. } \rightarrow \text { rather strong } \\
\text { expression }\end{array}$ \\
\hline $\begin{array}{l}\text { Profession } \\
\text { The center of expertise has initiated a participatory process for the development of a joint } \\
\text { definition of sustainability which has brought people from different fields together. Some of } \\
\text { whom are also working on interdisciplinary research projects with direct relevance to SD. } \\
\text { Sustainability is starting to be actively discussed, but is not yet dealt with in general lectures } \\
\text { and seminars. The handling of the HEI's sustainability paradigm differs markedly between } \\
\text { departments. } \rightarrow \text { low to medium expression }\end{array}$ \\
\hline $\begin{array}{l}\text { Organization } \\
\text { Many of the features of HEI VI already mentioned form a comprehensive organizational } \\
\text { structure. The center of expertise, the statute and the strategies to promote sustainability are } \\
\text { recognized as reasonable. However, the center of expertise's efforts to involve a more diverse } \\
\text { group of stakeholders in a structural way has so far not been as fruitful. Administrative } \\
\text { procedures have not been aligned with sustainability standards due to a lack of direction, in } \\
\text { spite of improved communication with senior management via the center of expertise. } \rightarrow \\
\text { medium to strong expression }\end{array}$ \\
\hline $\begin{array}{l}\text { Knowledge } \\
\text { SD-related knowledge at HEI VI consists of a variety of material that has been published by } \\
\text { the center of expertise or the HEI in general. The more extensive examples are the } \\
\text { sustainability report and a best practice compilation of different teaching formats for SD. } \\
\text { However, there is criticism of the fact that internal knowledge transfer is not sufficiently } \\
\text { pervasive and has not reached some key stakeholders preventing them from taking cohesive } \\
\text { action. } \rightarrow \text { low to medium expression }\end{array}$ \\
\hline $\begin{array}{l}\text { Public } \\
\text { There is currently some overlap between the knowledge and the public dimensions. } \\
\text { Accordingly, the public is addressed, but has not been reached in such a way as to establish } \\
\text { general awareness of the HEI's sustainability process. } \rightarrow \text { low expression }\end{array}$ \\
\hline
\end{tabular}

Figure 5. Overview of the cultural orientations and the governance dimensions of higher education institution (HEI) VI.

In light of the cultural orientation, some of the governance equalizer values do not come as a surprise. The HEI's low learning orientation, and in particular the fact that responsibility for SD is mainly assigned to senior management can facilitate and accelerate processes such as embedding SD in the mission statement ( $\rightarrow$ politics), especially when it is paired with a whole-institution approach $(\rightarrow$ organization, profession). However, in terms of long-term prospects, the success of such a top-down process depends on whether HEI members are willing and able to commit to a mission statement that they were not involved in developing. In order to bring a top-down strategy to life ( $\rightarrow$ politics, organization, public), it may be necessary either to allocate additional personnel specific responsibility for achieving the objectives or to re-organize responsibilities, because it is unlikely that staff will have 
too much time for unexpected tasks. Otherwise, a low learning orientation combined with a high holistic orientation towards SD might come in handy when it comes to announcing SD principles for the HEI as a whole, but it does not guarantee that such principles will be eagerly adopted.

As described above, the center of expertise has begun to promote an institution-wide conversation on SD ( $\rightarrow$ profession, knowledge) because of its belief in holistic transformation, but the power to make real changes to fundamental processes still lies with senior management, which does not take things quite so far. The thoughtfully constructed and broadly established center of expertise, which is striving to coordinate a diligent and coherent process ( $\rightarrow$ organization), may be in danger of becoming a toothless tiger. This might lead to problems for all the equalizer dimensions, since their development seems to depend on that very structure.

\subsubsection{Case VIII: Low Holistic and Profound Learning Orientation}

HEI VIII is also located in an urban environment. It also has 25,000-50,000 students across $100-200$ different study programs and employs up to 5000 people. Sustainability became an issue at this HEI at the beginning of the 1990s, sparked by employees in the administration who demanded that the institution take meaningful steps to reduce its energy consumption, much like case VI. At HEI VIII, this led to a long process of ISO certification and ultimately resulted in the introduction of the Eco-Management and Audit Scheme (EMAS). Several small sustainability teams were entrusted with the development of energy saving measures at the departmental level; these had a great impact and helped the whole process to evolve.

Nowadays, there is a staff unit for sustainability and energy with approximately ten employees, who are recognized as important drivers of the sustainability process. The concept of sustainability has broadened over time. Through, inter alia, the engagement of a student initiative, the focus has been shifted from campus management resource concerns towards a comprehensive approach including research, teaching and outreach. A research center acted as the key catalyst for sustainable development in research, generally accessible courses were established with a clear relevance for sustainability, and participation in sustainability networks was increased.

As stated above, HEI VIII is an institution with a relatively low holistic orientation and a relatively high learning orientation towards SD. Therefore, to some extent, it represents the reverse set-up of HEI VI. A closer look at the governance equalizer dimensions for HEI VIII, as summarized in Figure 6, might help to pinpoint the possible effects of the different cultural environment that is indicated on the left side of the figure.

Throughout the five dimensions, the high learning orientation seems to have had an impact that is manifested in a collaboratively developed mission statement $(\rightarrow$ politics, organization, profession, public) and also in the way the staff unit has been arranged ( $\rightarrow$ organization, knowledge). It has close links with senior management but is also working with sustainability teams in the HEI's different areas ( $\rightarrow$ profession). Responsibility for SD is spread between them and not completely centralized, which certainly increases public attention for the topic $(\rightarrow$ public). The HEI's learning orientation, and specifically its conception of its own role in society as an SD educator, has enabled the development of new concepts of knowledge transfer ( $\rightarrow$ knowledge, public).

The main gap highlighted by the governance equalizer is insufficient coherence and shared understanding amongst HEI members with regard to SD $(\rightarrow$ profession). Against the backdrop of a long tradition of ecological optimization and the ongoing focus on energy and resources in the staff unit, it seems logical that, despite collaborative processes, HEI members are irritated by aspects of the institution's concept of sustainability because the holistic orientation is somewhat limited. Nonetheless, the HEI has been able to establish solid overarching governance structures. 


\begin{tabular}{|c|c|}
\hline SD Cultural Orientations & Governance Equalizer Dimensions \\
\hline \multirow{3}{*}{$\begin{array}{l}\text { Learning orientation: The HEI } \\
\text { - pursues the idea of shared } \\
\text { responsibilities, } \\
\text { values the students as a great } \\
\text { driving force and has } \\
\text { identified actors in a range of } \\
\text { positions as being part of a } \\
\text { collective SD process, } \\
\text { has established a steering } \\
\text { committee that helps to bring } \\
\text { together the different views, } \\
\text { expectations and experiences, } \\
\text { recognizes senior management } \\
\text { commitment and support, but } \\
\text { focuses more on the broad } \\
\text { mass of HEI members, } \\
\text { stresses its role in society and } \\
\text { aims for SD especially through } \\
\text { its teaching activities. } \\
\rightarrow \text { relatively high expression }\end{array}$} & $\begin{array}{l}\text { Politics } \\
\text { The activities are well supported by the HEI's senior management. Despite the fact that } \\
\text { sustainability is not regarded as the key aspect of the institution's profile or a core issue, the } \\
\text { institution has put in place environmental guidelines and a sustainability mission statement. The } \\
\text { large staff unit and EMAS attest to a certain sense of responsibility for the SD process. Hence, the } \\
\text { equalizer dimension politics is rather well developed in case VIII. } \rightarrow \text { rather strong expression }\end{array}$ \\
\hline & $\begin{array}{l}\text { Profession } \\
\text { This dimension is not as well established. The mission statement was developed by means of a } \\
\text { collaborative process and the major student initiative for SD manages to bring together } \\
\text { representatives of the different fields of activity. However, HEI members complain about a lack of } \\
\text { shared goals or concepts, and the lack of a common language between the disciplines. Given the } \\
\text { starting point of the institution's sustainability process, aspects of climate change mitigation and } \\
\text { resource savings still receive more attention than other aspects of SD. } \rightarrow \text { medium expression }\end{array}$ \\
\hline & $\begin{array}{l}\text { Organization } \\
\text { The HEI has set up solid and effective structures that provide the engaged actors with agency and } \\
\text { room for proactive process design. Through arrangements such as the sustainability teams and a } \\
\text { steering committee mean that the needs of the individual fields in the HEI can be identified and } \\
\text { solutions found. It is only the derivation of measures from the mission statement that has been } \\
\text { insufficient. } \rightarrow \text { rather strong expression }\end{array}$ \\
\hline \multirow{2}{*}{$\begin{array}{l}\text { Holistic orientation: The HEI } \\
\text { - focuses more on ecological } \\
\text { aspects of SD than others due } \\
\text { to its history, but is aiming for } \\
\text { a more comprehensive } \\
\text { approach, } \\
\text { has a staff unit for } \\
\text { sustainability and energy } \\
\text { which is eager to broaden the } \\
\text { process and is supported by a } \\
\text { steering committee. } \\
\rightarrow \text { relatively low expression }\end{array}$} & $\begin{array}{l}\text { Knowledge } \\
\text { Knowledge and the public are both dimensions that have thus far had medium to low status at } \\
\text { HEI VIII so far. Knowledge is evident in a diverse range of experience and theoretical knowledge, } \\
\text { found mainly at the staff unit and the research center. However, systematic bundling, preparation } \\
\text { and provisioning have not been arranged. Knowledge transfer is enabled through projects such as } \\
\text { a program for high school students about sustainability and climate change, and the establishment } \\
\text { of a sustainability research network. } \rightarrow \text { medium expression }\end{array}$ \\
\hline & $\begin{array}{l}\text { Public } \\
\text { The institution generally addresses its public is through publicity for events (posters etc.) } \\
\text { undertaken by the different actors and through its website, but response levels leave room for } \\
\text { improvement. Thanks to the staff unit's affiliation to HEI senior management, the structure is } \\
\text { quite well-known. } \rightarrow \text { low to medium expression }\end{array}$ \\
\hline
\end{tabular}

Figure 6. Overview of the cultural orientations and governance dimensions of HEI VIII.

\subsubsection{Comparison of HEIs VI and VIII}

The strongest equalizer dimensions for HEIs VI and VIII are politics and organization. Profession, knowledge and public are all developed to a medium level at both HEIs. At first sight, the different organizational cultures do not appear to have had a particular impact on HEI sustainability governance. However, as the individual case descriptions have shown, the HEIs' SD structures vary with regard to some important details. This is most prominently expressed in the relations identified between the main SD actors and the potential for these relations to be shaped by the culture of the organization (especially its learning orientation).

HEI VI with its center of expertise and HEI VIII with its staff unit have set up structures that aim to introduce SD measures into all fields of activity. They both have close links with senior management and are equipped with roughly the same number of staff. However, there are differences in their strategic alignment and integration, i.e., the way functions are organized as shown in the equalizer. These relate to three major aspects, which seem to go hand in hand with the HEIs' cultural orientations: the manner of their outreach into the institution, their degree of autonomy and their conceptual focus.

By 'manner of outreach', we mean the strategies adopted by the two bodies that might help them to gain acceptance for (common) SD activities in the HEI's community. The idea that responsibility for SD should be spread across several pairs of shoulders ( $\rightarrow$ attribution of responsibility, as part of the learning orientation), and that these shoulders need to have some level of autonomy, seems to have driven HEI VIII towards more open and extensive structures. Certainly, the staff unit is the team with primary responsibility; it is also dependent on senior management decisions. But through the sustainability teams in different departments, a unifying steering committee and a good connection with the biggest and highly active student and staff sustainability initiative, they have the potential to shape a coherent and collaborative process that receives a broad welcome. The institution's learning orientation has thus enabled reasonable structures in terms of profession, organization, and potentially public.

This is seemingly less the case in HEI VI, where the working groups are an integral part of the center of expertise, are made up of appointed members and, therefore, act less independently. 
The structure is not bad per se, but it could be argued that greater awareness of and trust in a broader range of perspectives could help with implementation. This is evident at HEI VI in certain situations where senior management demonstrates a lack of appreciation for the achievements of extensive student engagement. The center of expertise, however, is working on overcoming this problem and is already considered a good contact point for SD issues by other HEI members. These efforts might eventually lead to changes in the HEI's cultural orientations. This would provide an example of how governance structures can influence an HEI's cultural orientation over time.

The conceptual focus refers to the aspects of SD that are being addressed by the staff unit or the center of expertise and their underlying conceptions of sustainability. Even though both HEIs originally focused on improving ecological rather than other aspects of sustainability, as the cultural orientations show, HEI VI is now applying a multi-dimensional approach more consistently than HEI VIII. This can be linked to the different staff configurations that are responsible for SD, and their backgrounds. On the one hand, the staff unit at HEI VIII has evolved from a staff unit for energy to a staff unit for sustainability and energy and was, therefore, built around — and still is dominated by-an expertise in energy and resource issues. The center of expertise in HEI VI, on the other hand, was conceived as an interdisciplinary team from the beginning and hence has been better able to identify with a multi-dimensional concept of sustainability.

When looking at overall SD governance at both HEIs, however, this head start has not resulted in a long-term advantage or disadvantage for HEI VI. This is doubtless due to a number of factors. It is suspected, though, that the conception of sustainability, which is only one part of the holistic orientation, might have less influence on SD governance than the second part, the relevance and scope of organizational change. At least regarding the initiation of the process, it seems to be more important for an HEI's SD governance to take an institution-wide approach than have a comprehensive conception of sustainability when structures are created, which can happen at any level and in any part of the institution. After all, the whole-institution approach is an aspect that these two HEIs have in common and that so far seems to have guided them in relation to structures. However, comparison of the two cases shows that the learning orientation needs to be factored in when designing the whole-institution approach and that a holistic orientation alone does not lead to all-encompassing structures and processes.

This last aspect suggests that the discrepancies between the two cultural assumptions, which were found only in HEIs VI and VIII out of the sample of eleven, are not only uncommon, but also, to some extent, counterproductive. A more linear evolution in orientation appears more desirable, although it does not necessarily mean an easy route of SD implementation as the comparison of the next two cases will illustrate.

\subsection{Cases III and IX: Low Holistic and Learning Orientation vs. Distinct Learning and Holistic Orientation}

Cases III and IX are intended to provide insight into how very different stages of cultural orientation affected governance structures at the HEIs in question. Case III had one of the lowest learning and holistic orientations and case IX one of the highest. Since they both represented cases where the relationship between holistic and learning orientation was linear, it was deemed of particular interest to investigate how these individual HEIs at the opposite ends of the proposed cultural orientation spectrum translate their cultures into governance measures. Many differences were identified between the two HEIs, but the most distinctive aspect arising from the comparison was their different approaches towards knowledge work in the context of SD as the following outlines illustrate.

\subsubsection{Case III: Low Holistic and Low Learning Orientation}

HEI III is an urban HEI with 25,000-50,000 students in 100-200 study programs and employs between 5000 and 10,000 people. The sustainability process was only begun in 2013 with a senior management decision to appoint a sustainability commissioner. Prior to that, a very active student initiative had been the only driver of sustainability-related change at an institutional level. 
The sustainability commissioner, who is a professor and, therefore, does not have extra time resources, has been given the support of a research assistant and the task of supervising a 5 year sustainability reporting process with the aim of proposing appropriate measures. By the time the interviews took place, the team had almost finished its inventory and was about to start using it to derive strategies. One central idea is the establishment of a Green Office for process stabilization and continuity.

Apart from this central process, different individual activities are taking place. The abovementioned student initiative and the general student committee organize SD events, promote sustainable consumption on campus and search for innovative mobility solutions. A mixed group of HEI members is focused on making the campus bike friendly. As regards teaching, practical interdisciplinary sustainability courses are being offered.

This description of HEI III paints the picture of an HEI that has set a sustainability process in motion with a comparatively low learning orientation towards SD and an initially rather one-dimensional and top-down approach. Figure 7 reflects on some further insights into the HEI's cultural orientation and outlines the governance equalizer dimensions.

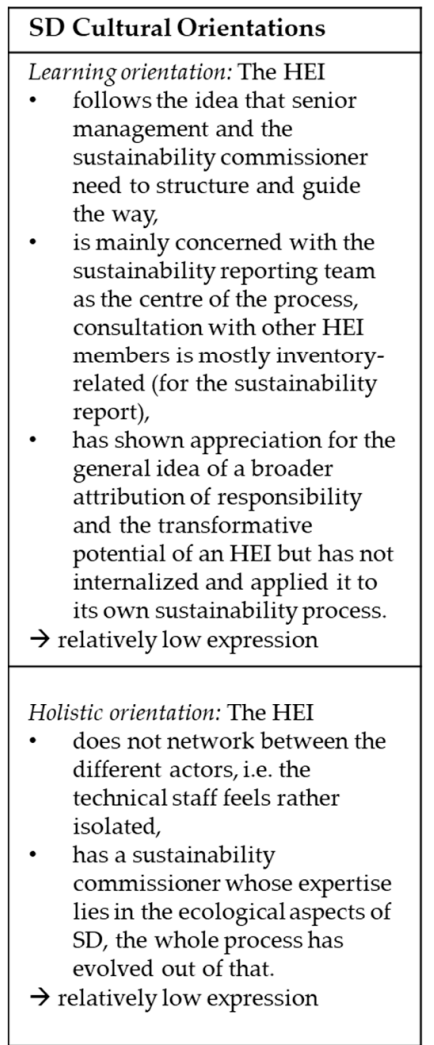

\begin{tabular}{l} 
Governance Equalizer Dimensions \\
\hline Politics \\
astainability guidelines are being discussed and the Copernicus Charta was signed early on \\
\hline Profession \\
Cooperation between different professions is enhanced through the range of interdisciplinary \\
courses on sustainable development and a certificate that students can receive for attending a \\
certain number of these courses. The sustainability reporting team reaches out to all relevant \\
actors for their inventory and slowly builds relationships with them. But the actors are not \\
actively networked with each other and collaboration is rather accidental. The technical \\
department in particular feels rather isolated, but also claims to have no resources to join in \\
any projects. In addition, there is no common understanding of sustainability. $\rightarrow$ medium \\
expression
\end{tabular}

Figure 7. Overview of the cultural orientations and governance dimensions of HEI III.

HEI III finds itself at a point in its sustainability process that can easily be traced back to its cultural orientation. The learning orientation in particular seems to be clearly reflected in the current governance. Senior management and the sustainability commissioner and his team preferred to learn about their institution before they learned with the institution when they decided that a sustainability report should be produced before any other centralized sustainability activities were pursued so that the latter could be based on reliable information ( $\rightarrow$ profession, organization, knowledge). It is arguable whether this was a wise or even necessary decision, and, in the long run, this will be illustrated by what the HEI eventually makes of the process that it has started, which it has mostly kept in the presidential office. For now, the activities taking place in addition to that official top-down process such as the sustainability certificate that students can gain—organized by some teaching staff, or other student or professional or technical staff-based initiatives-are trying in vain to find allies in their HEI. 
Instead of supporting the building of an SD network within the HEI and starting to share responsibilities, senior management prefers to join external sustainability networks and seek alliances with elite representatives from other HEIs. Both are a potential source of valuable knowledge on SD implementation, but the exclusive involvement of senior management underlines once more the HEI's low organizational learning orientation. The establishment of a Green Office (a student-led sustainability bureau with HEI funding) may succeed in breaking with this pattern ( $\rightarrow$ organization). So long as it is not primarily an extension of the senior management but has some autonomy, it could be a good way to open up the process to the whole HEI community ( $\rightarrow$ profession, public).

Taking the HEI's holistic orientation into consideration, it has certainly had an impact on the ongoing process. The HEI does intend to apply a multi-dimensional approach to sustainability and to integrate it into its different fields of activity, but this concept was formulated only relatively recently. Besides the commissioner and his team, who are responsible for SD across the whole institution $(\rightarrow$ organization), there are hardly any activities that indicate a comprehensive approach is being taken $(\rightarrow$ politics). Due to his area of expertise, the sustainability commissioner mainly takes content-based responsibility for ecological topics. In this case, this has hardly any effect on the process within the HEI as a whole, as there has thus far been virtually no contact with the technical staff of the HEI $(\rightarrow$ profession). The relatively low learning orientation is, therefore, preventing the equally low holistic orientation at HEI III from having an impact on procedures.

\subsubsection{Case IX: High Holistic and High Learning Orientation}

HEI IX is the only rural HEI in the selection. It has less than 1000 employees, between 5000 and 10,000 students and offers study programs in a narrow course spectrum. In 2013, some committed individuals at HEI IX started submitting requests to senior management for the HEI to promote sustainability. Some responsibility for SD was created in the form of target agreements between the HEI and the federal state. Institution-wide workshops in 2015 introduced further ideas about a sustainable HEI and were followed by the appointment of a sustainability commissioner, also a professor, who was provided with some personnel resources. The sustainability commissioner coordinates a SD working group that has prepared sustainability guidelines that were discussed in another institution-wide workshop including senior management and are being processed by the HEI senate.

The working group, which has a good mix of HEI members, and a student initiative host small events and participate in national sustainability action days. On the administrative side, sustainability considerations have impacted on a number of procurement decisions, and connections have been made between SD and the HEI's policies (e.g., gender equality, family friendliness, inclusion).

HEI IX has the most concise orientation of the four towards sustainability. Figure 8 provides more detailed information on both the cultural orientation and the governance equalizer. The interrelationship between the two is discussed below.

Interestingly, the governance equalizer does not actually portray HEI IX as having advanced sustainability structures and processes, as the organization's culture has suggested. However, that does not necessarily mean that the cultural orientations did not have an impact. Closer examination reveals that the structures and processes that have been implemented or are about to be implemented, especially in relation to politics and organization, do reflect a relatively high holistic and learning orientation.

The understanding that actors from all the different groups of stakeholders and fields of activity should have the opportunity to participate in the HEI's sustainability process is clearly expressed in the way the overall process has been executed so far. Several institution-wide workshops were held, which, among other things, resulted in common sustainability guidelines ( $\rightarrow$ politics, profession, public). The sustainability commissioner coordinates an open SD working group ( $\rightarrow$ organization), and student involvement is much appreciated, albeit difficult to maintain. From the very beginning, sustainability was considered to be a multi-dimensional concept, and this is well reflected in the guidelines. The steps may be small, but they set the tone for further development of the HEI's sustainability governance. This is especially true for the knowledge dimension, the least prominent equalizer dimension at HEI 
IX. This case indicates that participatory processes not only take time, but also require staff resources, with which HEI IX is the least equipped out of the four cases presented here. Apart from that, this HEI certainly has some advantages-shorter distances, a smaller range of disciplines-which facilitate some processes, since it is by far the smallest of the four HEIs.

\begin{tabular}{|c|c|}
\hline SD Cultural Orientations & Governance Equalizer Dimensions \\
\hline \multirow{3}{*}{$\begin{array}{l}\text { Learning orientation: The HEI } \\
\text { has so far undergone an } \\
\text { organic and collaborative } \\
\text { evolution of SD structures and } \\
\text { goals, } \\
\text { has established a working } \\
\text { group and hosted institution- } \\
\text { wide strategy workshops; both } \\
\text { support the exchange of view } \\
\text { and mutual learning for } \\
\text { sustainability, } \\
\text { is actively engaged with } \\
\text { regional actors and influences } \\
\text { regional development through } \\
\text { various projects. } \\
\rightarrow \text { relatively high expression }\end{array}$} & $\begin{array}{l}\text { Politics } \\
\text { Sustainability is certainly identified as a relevant issue on the political agenda of HEI IX. The } \\
\text { official approval of sustainability guidelines by the senate is underway and target agreements } \\
\text { with the federal ministry offer an important framework for initiatives. However, there are } \\
\text { complaints about a lack of a clear strategy. } \rightarrow \text { medium expression }\end{array}$ \\
\hline & $\begin{array}{l}\text { Profession } \\
\text { The working group serves as an effective network for people from different fields of activity, } \\
\text { and is yet characterized by a variety of individual definitions of sustainability and their } \\
\text { application for the HEI. SD is encountered in different ways by members of the different } \\
\text { disciplines, especially in the context of teaching and research. Nevertheless, there are a } \\
\text { number of (practical) seminars with a sustainability focus that are accessible for all students } \\
\text { and often provided in collaboration with external partners. The HEI's narrow range of } \\
\text { disciplines generally seems to favor more direct exchanges. } \rightarrow \text { medium to strong expression }\end{array}$ \\
\hline & $\begin{array}{l}\text { Organization } \\
\text { A clear course has been set with regard to structure. Further development and } \\
\text { implementation are needed. Offers to participate are increasingly recognized and accepted, } \\
\text { but student involvement is in question since several key players are leaving the HEI. } \rightarrow \\
\text { medium expression }\end{array}$ \\
\hline \multirow{2}{*}{$\begin{array}{l}\text { Holistic orientation: The HEI } \\
\text { has appointed a sustainability } \\
\text { commissioner with an } \\
\text { interdisciplinary background } \\
\text { and is taking a holistic and } \\
\text { collaborative approach to } \mathrm{SD}, \\
\text { considers all its fields of action } \\
\text { as equally relevant to SD. } \\
\rightarrow \text { relatively high expression }\end{array}$} & $\begin{array}{l}\text { Knowledge } \\
\text { This dimension still needs to be strengthened. A considerable amount of research and } \\
\text { teaching at HEI IX relates to sustainability issues and is constantly producing new knowledge, } \\
\text { but the transfer of this to the HEI itself has not yet been regulated. For now, sustainability } \\
\text { actions are based on single, somewhat unrelated ideas rather than systemic priorities. } \rightarrow \\
\text { rather low expression }\end{array}$ \\
\hline & $\begin{array}{l}\text { Public } \\
\text { There is a desire for greater public attention for, and knowledge of, the sustainability process } \\
\text { particularly from students. There are activities aiming, inter alia, to give the issue greater } \\
\text { prominence - such as the strategy workshops, the online presence, a lecture series on } \\
\text { sustainability and a sustainability guide produced by the student initiative. Nonetheless, } \\
\text { sustainability, or at least the awareness for the HEI's efforts, has by far not reached every } \\
\text { corner of the institution. } \rightarrow \text { low to medium expression }\end{array}$ \\
\hline
\end{tabular}

Figure 8. Overview of the cultural orientations and governance dimensions of HEI IX.

\subsubsection{Comparison of HEIs III and IX}

At first sight, there are some commonalities in the two institutions' sustainability processes. They started around the same time after small groups or individual HEI members became engaged with sustainability. Once they had been successful in putting sustainability on the HEI's agenda, the senior management team in question decided to appoint a sustainability commissioner to be responsible for coordinating and overseeing the whole process. What appears to be quite different, though, is the conception of how best to set up the process. This is where the cultural orientations divide the two HEIs.

Although in the case of both HEIs, it has been a similarly short time since they initiated their sustainability processes, they have already adopted very different positions. It can be assumed that their cultural orientations have played a role in organizational development towards sustainability. HEI III went straight to action with a clear vision and introduced structures that should form the basis for a well-founded process. From an operational perspective, this makes sense, but the essence of sustainability seems to have been neglected or not fully internalized yet. This means that sustainable development, with its various substantive and methodological components, has either not been fully explored or has been reduced to distinct individual aspects. Even though the will to implement a multi-dimensional understanding of sustainability in all areas of the institution ( $\rightarrow$ holistic orientation) is generally present, the HEI is still faced with the challenge of transferring this will to the current elite and discrete structures and thus developing them further to make them more accessible. As was the case at HEI IX, the HEI's organization and profession dimensions would certainly benefit from such a concept. 
HEI IX started with somewhat less concrete activity, but active stakeholder participation ensured that there was broad agreement with the central decision by senior management to appoint a sustainability commissioner. This openness signals to the members of the HEI that their engagement is wanted and that it can shape important aspects of SD. This also makes it easier to replicate the organizational culture amongst HEI members and encourage it to evolve collectively. The working group has promoted regular interdisciplinary exchange and collaboration $(\rightarrow$ organizational learning orientation). Nonetheless, there is one equalizer dimension that has been developed notably further at HEI III than HEI IX: knowledge.

Maybe unexpectedly, this is also where the differences between the ways the HEIs' governance has been shaped by their cultural orientations are most obvious. The HEIs seem to apply quite different approaches towards knowledge and knowledge work in the context of SD. HEI III, with its focus on knowledge generation, has introduced a structure, namely the sustainability reporting team, which is efficient at gathering data and identifying important contributors for the report. Their knowledge work is a highly centralized and isolated process that does not open up to the potential for common exploration with diverse stakeholders on diverse topics, which is the approach taken by HEI IX. The combination of low holistic orientation and low learning orientation leads HEI III to a very target-oriented, and in that sense efficient, knowledge dimension that, however, will inevitably reach its limits when all information has been gathered. High holistic and learning orientations have helped HEI IX to lay groundwork that gives knowledge the chance to expand at a variety of levels. The downside of this approach is certainly that it takes much more effort in relation to proactive stakeholder engagement and coordination and, therefore, has not yet resulted in a strong knowledge dimension for HEI IX. This comparison of knowledge work captures the distinct styles of SD implementation at both HEIs and corresponds well with the aforementioned aspects. It also highlights the different qualities that can be found within a single equalizer dimension and encourages an integrative approach towards the governance equalizer when introducing governance measures.

Overall, neither of the two HEIs has addressed any of the equalizer dimensions in an all-encompassing way. They have made approximately the same amount of progress, if that is even comparable, and are now at a point where the implementation of concrete and significant measures is required. Their SD processes are relatively young and will need some more time to unfold. It remains to be seen whether they will manage to either seize or change their current functions and culture.

\section{Discussion and Conclusions}

The comparisons between HEIs VI and VIII and HEIs III and IX have revealed various ways in which the cultural orientations of HEIs are expressed in the functionalities of their SD governance. In each of the individual cases, it was in principle possible to understand the relationship between these two factors. But what general conclusions can be drawn from these observations?

It is certainly a central finding that the cases not only demonstrate an interplay between cultures and functions, but also that the individual cultural orientations interlock during the implementation of structures, etc., and usually produce a common result. It is unlikely to be possible to cite single cultural orientations, be they holistic or learning, that have clearly and directly affected and shaped individual governance dimensions. This is not least due to the fact that neither cultures nor governance dimensions can always be clearly separated, nor should they be during the consideration of governance measures. Ultimately, HEI sustainability processes are no 'optimized production lines'; they are instead complex social processes that are both, resulting from and leading to social innovations (e.g., [16,27,34]). This is precisely why consideration of organizational cultures is so relevant and why it is worth attempting to identify patterns hampering or supporting fundamental change.

Another essential aspect that emerges from the comparative case analysis is the observation that cultural orientations do not become visible instantaneously and simultaneously in all corners of an HEI. This is in line with approaches of organizational research according to which HEIs may be considered as what is labelled "loosely coupled systems" in which autonomy and cohesion apply at the same time 
which allows for testing novel solutions without reaching out to the whole institution right from the beginning [35]. Particularly in large HEIs, there may be "communities within communities" that do not interact as intensely with each other [36] so that a cultural change in one sector does not immediately apply for another one. Apart from this theoretical consideration, the challenge of grasping the cultural orientation of HEIs is partly due to the underlying methodology and material used. For the study reported here, we subjected existing interview material, i.e., material collected for a different purpose, to secondary analysis. Therefore, we did not have access to all the information that would have been desirable to enable the cases to be explored in greater depth. The cultural orientations described here need time to develop and to influence governance structures. This also brings into play what has already been suggested by some of the four cases, namely the possibility that structures and processes implemented may in turn have an impact on cultural orientations, thus giving rise to a feedback loop as part of a living process, as Disterheft et al. [10] have also pointed out with regards to participatory processes in particular.

The analysis has shown, in some cases, that the most direct path from cultures to functions was via the elements assigned to politics and/or organization. For at least three of the HEIs considered (III, VI and VIII), these governance equalizer dimensions were initially in the foreground. It is quite possible that this reflects a pattern that also appears in other cases from the overall sample. However, there are certainly other ways for SD to get into the HEIs' bloodstreams. For instance, informal and unofficial but significant and profound engagement for SD by a group of actors might favor the development of a collaborative network of HEI members before it seeks to become institutionalized [37]. It, therefore, remains to be seen how successful the approaches will prove to be in the long run and what advantages and disadvantages they each offer. A broader examination of the whole study sample, ideally in combination with a second survey at the same HEIs, could provide insight into this.

This exploratory study, based on a secondary analysis of existing interviews, has identified interesting starting points for further research and, building on Adams et al. [16] and Baker-Shelley et al. [17], has also expanded the understanding of the importance of organizational cultures for sustainable development in HEIs. Real-life examples were used to illustrate potential interdependencies and to draw some general conclusions about how the cultures and functions of HEI governance relate to each other. In particular, it has increased the awareness of the diversity of HEIs' SD processes. No matter how similar some structures may appear, it is not uncommon for details that initially appear inconspicuous to have a significant impact on their success. Both comparisons have made this clear. What was also implied at some points was the need to recognize further factors that influence an HEI's sustainability governance beyond its cultural orientation. Aspects such as the size of the HEI or regional (political, legal and socio-economic) circumstances certainly also need to be factored in and might show some of the SD processes discussed in another light. Some of these aspects are also very likely to have shaped the depicted organizational cultures. However, this opens a new discussion that requires further investigation and exceeds the material of this study.

Overall, the frameworks taken from Bauer et al. [2] and Niedlich et al. [19] have proven themselves to be useful analytical tools. The categories developed provided valuable guidance in the midst of the complexities of HEI SD governance. This combined analysis, enriched by the four case studies, identified some fine mechanisms that can take place at the interplay of culture and functions. At the same time, it enabled a new reflection on the original frameworks themselves. Future research can take this into consideration and also explore other ways of applying them.

In view of the small selection of cases, which is also limited to German HEIs involved in a joint project, the limits of generalizability are quickly reached. The interpretative methodology also imposes certain limitations on the results here. Further investigation on the basis of a larger sample is required in order to verify the findings. Nevertheless, the approach adopted in this paper contributes to the development of instruments that can be applied in practice, e.g., for self-reflection and self-assessment by HEIs (see [38]). It could also serve to further differentiate and operationalize the cultural dimensions for the purpose of standardized surveys or be applied to the development of counselling concepts. 
Bearing the initial research question of this paper in mind, it can be stated that an HEI's organizational culture is highly likely to affect its approach to SD governance in crucial ways. The case studies demonstrated essential connections between cultural orientations and the governance approaches of HEIs, as illustrated by the governance equalizer. Many of these connections relate to the specific circumstances of the HEIs in question, i.e., with regard to the individuals involved. Although there will be no other HEI that functions in exactly the same way as one of these four, the perspective offered by this combined analysis of cultures and functions of SD governance at HEIs offers should make it easier to identify trends.

Author Contributions: Conceptualization, M.B., S.N., M.R., I.B. and L.J.; methodology, M.B., S.N., M.R. and I.B.; validation, M.B., S.N., M.R., I.B. and L.J.; formal analysis, M.B., S.N., M.R., I.B. and L.J.; writing-original draft preparation, M.B.; writing-review and editing, M.B., S.N., M.R., I.B. and L.J.; visualization, M.B., S.N., M.R. and I.B.; supervision, M.R. and I.B.; project administration, S.N., M.B. and M.R.; funding acquisition, M.R. and I.B. All authors have read and agree to the published version of the manuscript.

Funding: This research was funded by the Bundesministerium für Bildung und Forschung, Grant/Award Number: 13NKE007A.

Acknowledgments: We thank four anonymous reviewers for their feedback on an earlier version of this paper.

Conflicts of Interest: The authors declare no conflict of interest.

\section{References}

1. Rinaldi, C.; Cavicchi, A.; Spigarelli, F.; Lacchè, L.; Rubens, A. Universities and smart specialisation strategy: From third mission to sustainable development co-creation. Int. J. Sustain. Higher. Educ. 2018, 19, 67-84. [CrossRef]

2. Leal Filho, W.; Wu, Y.-C.J.; Brandli, L.L.; Avila, L.V.; Azeiteiro, U.M.; Caeiro, S.; Madruga, L.R. Identifying and overcoming obstacles to the implementation of sustainable development at universities. J. Integr. Environ. Sci. 2017, 14, 93-108. [CrossRef]

3. Bauer, M.; Bormann, I.; Kummer, B.; Niedlich, S.; Rieckmann, M. Sustainability Governance at Universities: Using a Governance Equalizer as a Research Heuristic. High. Educ. Policy 2018, 31, 491-511. [CrossRef]

4. Awuzie, B.O.; Abuzeinab, A. Modelling Organisational Factors Influencing Sustainable Development Implementation Performance in Higher Education Institutions: An Interpretative Structural Modelling (ISM) Approach. Sustainability 2019, 11, 4312. [CrossRef]

5. Weisser, C.R. Defining sustainability in higher education: A rhetorical analysis. Int. J. Sustain. Higher Educ. 2017, 18, 1076-1089. [CrossRef]

6. Lozano, R.; Ceulemans, K.; Alonso-Almeida, M.; Huisingh, D.; Lozano, F.J.; Waas, T.; Lambrechts, W.; Lukman, R.; Hugé, J. A review of commitment and implementation of sustainable development in higher education: Results from a worldwide survey. J. Clean. Prod. 2015, 108, 1-18. [CrossRef]

7. Rath, K.; Schmitt, C.T. Sustainability at Universities: Degrees of Institutionalization for Sustainability at German Higher Education Institutions-A Categorization Pattern. In Handbook of Theory and Practice of Sustainable Development in Higher Education: Volume 1; Leal Filho, W., Brandli, L., Castro, P., Newman, J., Eds.; Springer International Publishing: Cham, Switzerland, 2017; pp. 451-470. ISBN 9783319478678.

8. Leal Filho, W. Education for Sustainable Development in Higher Education: Reviewing Needs. In Transformative Approaches to Sustainable Development at Universities; Leal Filho, W., Ed.; Springer International Publishing: Cham, Switzerland, 2015; pp. 3-12. ISBN 978-3-319-08836-5.

9. Mader, C.; Scott, G.; Abdul Razak, D. Effective change management, governance and policy for sustainability transformation in higher education. Sustain. Account. Manag. Policy J. 2013, 4, 264-284. [CrossRef]

10. Spira, F.; Tappeser, V.; Meyer, A. Perspectives on Sustainability Governance from Universities in the USA, UK, and Germany: How do Change Agents Employ Different Tools to Alter Organizational Cultures and Structures? In Sustainability Assessment Tools in Higher Education Institutions: Mapping Trends and Good Practices around the World; Caeiro, S., Leal Filho, W., Jabbour, C., Azeiteiro, U.M., Eds.; Springer: Cham, Switzerland, 2013; pp. 175-187. ISBN 978-3-319-02374-8. 
11. Shriberg, M.P. Sustainability in U.S. Higher Education: Organizational Factors Influencing Campus Environmental Performance and Leadership. Ph.D. Thesis, University of Michigan, Ann Arbor, MI, USA, 2002.

12. Disterheft, A.; Caeiro, S.; Azeiteiro, U.M.; Filho, W.L. Sustainable universities - a study of critical success factors for participatory approaches. J. Clean. Prod. 2015, 106, 11-21. [CrossRef]

13. Scott, G.; Tilbury, D.; Sharp, L.; Deane, E. Turnaround Leadership for Sustainability in Higher Education. Executive Summary; Project Report. 2012. Available online: http://sustainability.edu.au/material/teaching-materials/ turnaround-leadership-sustainability-higher-education-olt-funded-project-and-report/ (accessed on 28 February 2020).

14. Moore, J.; Pagani, F.; Quayle, M.; Robinson, J.; Sawada, B.; Spiegelman, G.; van Wynsberghe, R. Recreating the university from within. Int. J. Sustain. Higher Educ. 2005, 6, 65-80. [CrossRef]

15. Cameron, K.S.; Quinn, R.E. Diagnosing and Changing Organizational Culture. Based on the Competing Values Framework, Rev. ed.; Jossey-Bass: San Francisco, CA, USA, 2006; ISBN 978-0-7879-8283-6.

16. Baker-Shelley, A.; van Zeijl-Rozema, A.; Martens, P. A Conceptual Synthesis of Organisational Transformation: How to Diagnose, and Navigate, Pathways for Sustainability at Universities? J. Clean. Prod. 2017, 145, 262-276. [CrossRef]

17. Adams, R.; Martin, S.; Boom, K. University culture and sustainability: Designing and implementing an enabling framework. J. Clean. Prod. 2018, 171, 434-445. [CrossRef]

18. Sterling, S. Higher Education, Sustainability, and the Role of Systemic Learning. In Higher Education and the Challenge of Sustainability: Problematics, Promise, and Practice; Corcoran, P.B., Wals, A.E.J., Eds.; Kluwer Academic Publishers: Dordrecht, The Netherlands, 2004; pp. 49-70.

19. Niedlich, S.; Kummer, B.; Bauer, M.; Rieckmann, M.; Bormann, I. Cultures of sustainability governance in higher education institutions: A multi-case study of dimensions and implications. High. Educ. Q. 2019, 1-18. [CrossRef]

20. Wu, Y.-C.J.; Shen, J.-P. Higher education for sustainable development: A systematic review. Int. J. Sustain. High. Educ. 2016, 17, 633-651. [CrossRef]

21. Sylvestre, P.; Wright, T.; Sherren, K. Exploring Faculty Conceptualizations of Sustainability in Higher Education: Cultural Barriers to Organizational Change and Potential Resolutions. J. Educ. Sustain. Dev. 2013, 7, 223-244. [CrossRef]

22. Hoover, E.; Harder, M.K. What lies beneath the surface? The hidden complexities of organizational change for sustainability in higher education. J. Clean. Prod. 2015, 106, 175-188. [CrossRef]

23. Singer-Brodowski, M.; Etzkorn, N.; von Seggern, J. One Transformation Path Does Not Fit All-Insights into the Diffusion Processes of Education for Sustainable Development in Different Educational Areas in Germany. Sustainability 2019, 11, 269. [CrossRef]

24. Leal Filho, W.; Shiel, C.; Paco, A.; Mifsud, M.; Veiga Ávila, L.; Brandli, L.L.; Molthan-Hill, P.; Pace, P.; Azeiteiro, U.M.; Ruiz Vargas, V.; et al. Sustainable development goals and sustainability teaching at universities: Falling behind or getting ahead of the pack? J. Clean. Prod. 2019, 232, 285-294. [CrossRef]

25. Holm, T.; Sammalisto, K.; Grindsted, T.S.; Vuorisalo, T. Process framework for identifying sustainability aspects in university curricula and integrating education for sustainable development. J. Clean. Prod. 2015, 106, 164-174. [CrossRef]

26. Davis, H.; Goedegebuure, L. Governance for sustainability in higher education. In Ethics in Higher Education: Values-Driven Leaders for the Future; Singh, D., Stückelberger, C., Eds.; Globethics.net Education Ethics 1; Globalethics.net: Geneva, Switzerland, 2017; pp. 217-230. Available online: https://www.globethics.net/ documents/4289936/20368389/GE_Education_Ethics_1_isbn9782889311644.pdf (accessed on 31 March 2020).

27. Trencher, G.; Yarime, M.; McCormick, K.B.; Doll, C.N.H.; Kraines, S.B. Beyond the third mission: Exploring the emerging university function of co-creation for sustainability. Sci. Publ. Policy 2014, 41, 151-179. [CrossRef]

28. De Boer, H.; Enders, J.; Schimank, U. On the Way towards New Public Management? The Governance of University Systems in England, the Netherlands, Austria, and Germany. In New Forms of Governance in Research Organizations: Disciplinary Approaches, Interfaces and Integration; Jansen, D., Ed.; Springer: Dordrecht, The Netherlands, 2007; pp. 137-152. ISBN 978-1-4020-5830-1. 
29. Franz, K.; Brüsemeister, T. Gegenstandsbezogene Analyse sozialer Welten des BNE-Transfers. In Governance-Regime des Transfers von Bildung für Nachhaltige Entwicklung; Bormann, I., Hamborg, Eds.; Springer Fachmedien Wiesbaden: Wiesbaden, Germany, 2016; pp. 67-88. ISBN 978-3-658-13222-4.

30. Morse, J.M. Designing funded qualitative research. In Handbook of Qualitative Research, 4th ed.; Denzin, N.K., Ed.; SAGE: Thousand Oaks, CA, USA, 1994; pp. 220-235.

31. Dresing, T.; Pehl, T. Praxisbuch Interview, Transkription E Analyse. Anleitungen und Regelsysteme für Qualitativ Forschende, 8th ed.; Dr. Dresing und Pehl GmbH: Marburg, Germany, 2018.

32. Kuckartz, U. Qualitative Inhaltsanalyse. Methoden, Praxis, Computerunterstützung; Beltz-Juventa: Weinheim, Germany, 2012; ISBN 9783779928157.

33. Kyburz-Graber, R. Case Study Research on Higher Education for Sustainable Development. Epistemological Foundation and Quality Challenges. In Routledge Handbook of Higher Education for Sustainable Development; Barth, M., Michelsen, G., Rieckmann, M., Thomas, I., Eds.; Routledge: Abingdon, UK; New York, NY, USA, 2016; pp. 126-141.

34. Howaldt, J. New Pathways to Social Change-Creating Impact through Social Innovation Research. In Proceedings of the Conference "Impact of Social Sciences and Humanities for a European Research Agenda Valuation of SSH in mission-oriented research", Vienna, Austria, 28-29 November 2018; pp. 37-48.

35. Orton, J.D.; Weick, K.E. Loosely Coupled Systems: A Reconceptualization. Acad. Manag. Rev. 1990, 15, 203-223. [CrossRef]

36. Gurbutt, D.J.; Cragg, R.M. A community within a community. In Culture, Change and Community in Higher Education: Building, Evolving and Re-Building Learning Environments; Gurbutt, D.J., Cragg, R.M., Eds.; Routledge: Abingdon, UK; New York, NY, USA, 2019; pp. 69-76. ISBN 0367183447.

37. Schopp, K.; Bornemann, M.; Potthast, T. The Whole-Institution Approach at the University of Tübingen: Sustainable Development Set in Practice. Sustainability 2020, 12, 861. [CrossRef]

38. Niedlich, S.; Bauer, M.; Doneliene, M.; Jaeger, L.; Rieckmann, M.; Bormann, I. Assessment of Sustainability Governance in Higher Education Institutions-A Systemic Tool Using a Governance Equalizer. Sustainability 2020, 12, 1816. [CrossRef] 